\title{
A vitivinicultura de altitude em Santa Catarina (Brasil): espaços privilegiados para o turismo
}

\section{The altitude viticulture in Santa Catarina (Brazil): privileged spaces for tourism}

\author{
Flavia Baratieri Losso (LOSSO, F. B.) ${ }^{*} \mathrm{e}$ \\ Raquel Maria Fontes do Amaral Pereira (PEREIRA, R. M. F. do A.) ${ }^{* *}$
}

RESUMO - Este estudo, de caráter preliminar, buscou caracterizar o desenvolvimento da produção de vinhos de altitude em Santa Catarina (Brasil). A área objeto deste estudo centrou-se nos três pólos produtores de Vinhos finos de Altitude: São Joaquim, Caçador e Campos Novos. Como referencial teórico-metodológico utilizou-se o paradigma de formação sócio-espacial proposto por Milton Santos (1977) aliado às ideias difundidas por André Cholley (1964). Recorreu-se, igualmente, ao aporte teórico aplicado por Armen Mamigonian (1986) em seus estudos sobre o sul do Brasil. Desta forma, optouse pela realização de uma pesquisa histórica, de abordagem qualitativa. A coleta de dados deu-se através da pesquisa bibliográfica e documental. Em Santa Catarina, o surgimento da vitivinicultura é marcado pela imigração italiana formando as tradicionais regiões produtoras de vinhos do estado. Contudo, percebeu-se que os investidores da vitivinicultura de altitude de Santa Catarina tiveram seu olhar empreendedor despertado para o universo do vinho de uma forma muito pessoal, como por exemplo, suas origens italianas, a possibilidade de diversificação de atividade e de reinvestimento de capital e a reestruturação produtiva de sua antiga empresa vitícola. $O$ fortalecimento da imagem do vinho brasileiro perante o consumidor passa pelo enoturismo, para o qual a composição de um produto enoturístico completo deve ser considerada como ferramenta de marketing e aprimorada pelas empresas vitivinícolas de altitude.

Palavras-chave: Vitivinicultura de Altitude; Novas Regiões; Enoturismo; Santa Catarina.

ABSTRACT - This paper presents a preliminary study which sought to characterize the development of the production of altitude wines in Santa Catarina State (Brazil). The subject area of this study focused on the three producer poles of altitude wines: São

\footnotetext{
* Formação: Graduação e Mestrado em Turismo e Hotelaria pela Universidade do Vale do Itajaí (UNIVALI). Doutoranda pelo Programa de Pós-Graduação em Geografia da Universidade Federal de Santa Catarina (UFSC). Desde 2007 ocupa o cargo efetivo de professora de ensino básico, técnico e tecnológico do Instituto Federal de Santa Catarina (IFSC) - Campus Florianópolis Continente, atuando principalmente na área de restaurantes e hospitalidade, em cursos técnicos e superiores de tecnologia. Endereço físico para correspondência: Rua Otávio Cruz, 404, ap. 201 (Campeche). CEP: 88063-620 Florianópolis - Santa Catarina (Brasil). Telefone: (48) 9119-1331. Email: flablosso@ gmail.com

** Formação: Licenciatura em Geografia pela Universidade Federal de Santa Catarina (UFSC). Mestre em Educação pela Universidade Federal de Santa Catarina (UFSC). Doutorado em Geografia Humana pela Universidade de São Paulo (USP). Professora do Programa de Mestrado em Turismo e Hotelaria da Universidade do Vale do Itajaí (UNIVALI). Professora participante do Programa de Pós-Graduação em Geografia da UFSC e bolsista de Produtividade em Pesquisa do CNPq. Endereço físico para correspondência: Rua Uruguai, 458 (Centro). CEP: 88302202 - Itajaí - Santa Catarina (Brasil) - Caixapostal: 360. Telefone: (47) 3417500 - Ramal: 763. Email: raquelfontespereira@ gmail.com
} 
Joaquim, Caçador e Campos Novos. As a theoretical and methodological framework was used the paradigm of Social-Spatial Formation proposed by Milton Santos (1977) associated to the ideas disseminated by André Cholley (1964). The study also resorted to the theoretical approach applied by Armen Mamigonian (1986) in his studies of southern Brazil. Thus, it was chosen to perform an historical research, with a qualitative approach. The data collection was made through bibliographic and documentary research. In Santa Catarina State, the emergence of viticulture is marked by the Italian immigration which formed the traditional producer regions in state. However, it was noticed that the altitude wine industry investors of Santa Catarina had their entrepreneurial vision to the wine world in a very personal way, for instance, their Italian origin, the possibility of diversifying the activity and capital reinvestment and productive restructuring of its old wine company. The strengthening of the Brazilian wine image to the consumer go through the wine tourism, which the composition of a complete wine tourism product should be considered as a marketing tool and improved by altitude wine companies.

Key words: Altitude Viticulture; New Regions; Wine Tourism; Santa Catarina. 


\section{INTRODUÇÃO}

A região catarinense produtora de vinhos finos de altitude constitui a área objeto deste estudo, tendo como foco central retratar sua recente instalação, bem como de que forma vem se dando a sua evolução e o panorama atual, considerando a sua perspectiva de expansão a ponto de se tornar um novo produto e atrativo para enoturismo. Dentro desse quadro, faz-se necessário considerar as sensíveis modificações que têm afetado o mercado global e nacional de vinhos finos, no que se refere à produção, à comercialização e ao consumo desta bebida, favorecendo a inserção de novos produtos e de novas regiões produtoras em diversas regiões do mundo.

Conforme o Instituto Brasileiro do Vinho - IBRAVIN (2014) a área de produção vitivinícola no Brasil soma 83,7 mil hectares, se consolidando como o quinto maior produtor da bebida no Hemisfério Sul e é considerado um dos mercados vitivinícolas que cresce mais rapidamente no mundo. A vitivinicultura brasileira é encontrada em dez estados do país, segundo Protas e Camargo, 2011, que são: Rio Grande do Sul, Santa Catarina, Paraná, São Paulo, Minas Gerais, Espírito Santo, Goiás, Mato Grosso, Bahia e Pernambuco (Vale do Sub-Médio do São Francisco), todos com suas particularidades e formação bem distintas.

Cabe salientar que a região da Serra Gaúcha (Rio Grande do Sul/RS) e as regiões do Vale do Rio do Peixe e Litoral Sul (Santa Catarina/SC) se destacam como regiões tradicionais, ainda que haja um constante surgimento de novas regiões produtoras nas últimas décadas, como por exemplo, o Planalto Catarinense (SC) e a Campanha Gaúcha (RS) (PROTAS; CAMARGO, 2011; LOSSO, 2010; CORDEIRO, 2006).

Destaca-se que a organização do setor produtivo e o comércio de vinhos vêm passando por um acelerado processo de transformação, imposto pela reconfiguração da vitivinicultura mundial (AGUIAR, 2008). A autora argumenta que a reconfiguração identificada na cadeia produtiva de vinhos vem ocorrendo desde a década de 1980, motivada por uma série de transformações no processo produtivo, na comercialização e no consumo do vinho marcado por aspectos socioambientais. 
A expansão da vitivinicultura para a produção de vinhos finos ${ }^{1}$, no lugar da produção de vinhos de mesa ${ }^{2}$ vem ocorrendo em diferentes regiões do Brasil nas últimas décadas e está relacionada a dois conjuntos de fatores, fundamentalmente: à migração de gaúchos e catarinenses que em sua maioria possuem descendência italiana e a investimentos inovadores de outros setores da economia (FALCADE, 2011).

O processo evolutivo da vitivinicultura brasileira foi marcado pela chegada dos imigrantes italianos ao estado do Rio Grande do Sul (PROTAS; CAMARGO, 2011; DALCIN, 2008). Tonietto (2003a) considera entre 1870 e 1920 como o primeiro período da vitivinicultura no país onde se deu sua implantação, com ênfase nos vinhos de uvas americanas; o segundo período foi entre 1930 e 1960 através da diversificação de produtos com a introdução de vinhos de uvas híbridas e de uvas viníferas; na terceira fase ocorreu o incremento da qualidade e a oferta de vinhos varietais, entre 1970 e 1990; e, portanto, a partir dos anos 2000 tem início o quarto período em que se constata uma busca pela identidade do vinho brasileiro através da produção de vinhos de qualidade produzidos em determinadas regiões.

Como parte das consequências da reconfiguração mundial da vitivinicultura vem ocorrendo o cultivo de uvas das variedades de castas europeias e a produção de vinhos em regiões de elevada altitude na Costa Rica, no Quênia, na Bolívia, em Portugal (Alentejo), na Argentina (Salta) (LALAS, 2013) e também no Brasil em Santa Catarina, nas regiões próximas a São Joaquim, Caçador e Campos Novos desde o final da década de 1990 (LALAS, 2013; LOSSO, 2010; BLUME; HOFF; PEDROZO, 2007). Esses empreendimentos foram instalados distantes dos paralelos $30^{\circ}$ e $50^{\circ}$, área considerada ideal para o cultivo da vinha, pois, conforme Losso e Pereira (2012), os empresários e especialistas catarinenses defendem que a combinação de tipo de solo, volume médio de chuvas, temperatura média anual e especialmente a amplitude térmica significativa oferecem condições adequadas para a obtenção de vinhos finos de qualidade e competitivos no atual mercado vitivinícola.

\footnotetext{
${ }^{1}$ Vinho fino é o vinho de teor alcoólico de 8,6\% a $14 \%$ em volume, elaborado mediante processos tecnológicos adequados que assegurem a otimização de suas características sensoriais e exclusivamente de variedades Vitis vinífera do grupo Nobres, a serem definidas em regulamento, conforme Lei $\mathrm{n}^{\circ} 10.970$, de 12 de novembro de 2004 (BRASIL, 2004a).

${ }^{2}$ Os vinhos em cujo rótulo conste apenas o termo "Vinho de Mesa" foram elaborados apenas a partir de uvas americanas. Essa distinção tornou-se necessária no Brasil, já que o país, por fatores econômicos ou culturais, é um dos poucos que permite a produção de vinhos com uvas americanas (Vitis labrusca, Vitis rupestris, Vitis riparia e Vitis bourquina) (MILAN, 2010).
} 
No caso da produção de vinhos finos de altitude em Santa Catarina, municípios de três regiões produtoras são destacados desde a constituição, em 2005, da Associação Catarinense de Produtores de Vinhos Finos de Altitude - ACAVITIS, que são: Campos Novos (abrangendo os municípios de Campos Novos e Monte Carlo), Caçador (que inclui Caçador, Água Doce, Salto Veloso, Treze Tílias, Videira e Tangará) e São Joaquim (formada por São Joaquim, Urupema, Urubici, Bom Retiro, Painel e Campo Belo do Sul), conforme demonstrado na figura 1.

É importante destacar que o capital destes empreendedores dos vinhos finos de altitude de Santa Catarina vem, na maioria dos casos, de diferentes setores, como o setor têxtil, o cerâmico, a fruticultura, a pecuária e até mesmo de profissionais liberais da área da saúde, que por interesse pessoal, frequentemente relacionado à suas histórias familiares, elegeram investir aportes significativos na vitivinicultura de altitude (LOSSO, 2010; PROTAS; CAMARGO, 2011).

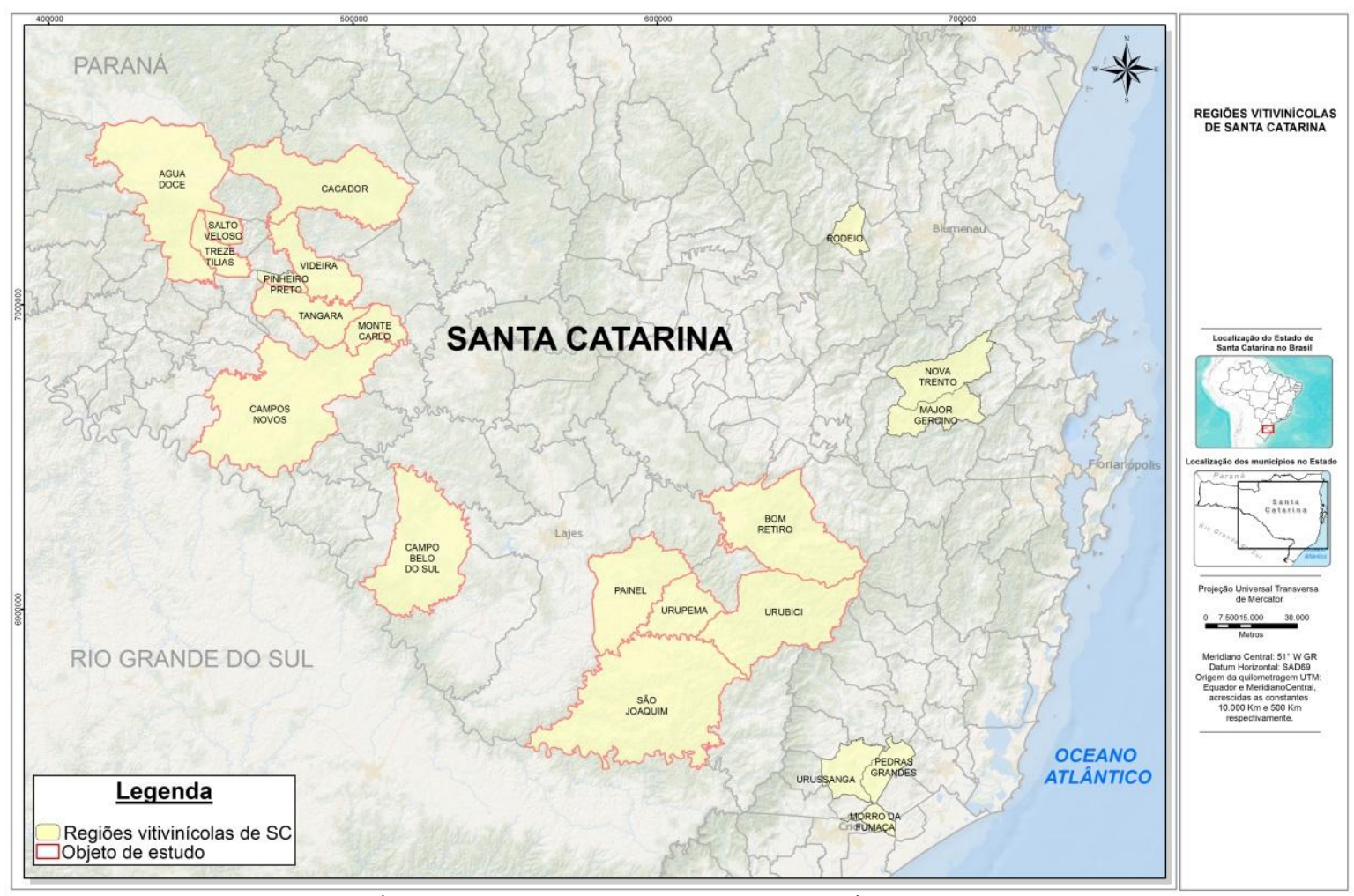

FIGURA 1 - REGIÕES VITIVINÍCOLAS DE SANTA CATARINA E ÁREA OBJETO DE ESTUDO. Elaboração: Flavia Baratieri Losso e Renata Duzzioni, 2014.

Fonte: LOSSO; PEREIRA, (2012); PROTAS; CAMARGO, (2011); BRDE, (2005).

O fortalecimento da imagem do vinho brasileiro perante o consumidor passa pelo enoturismo, para o qual a composição de um produto enoturístico completo deve 
ser considerada e aprimorada pelas vinícolas brasileiras como ferramenta de marketing (FLORES; FLORES, 2012).

\begin{abstract}
O desenvolvimento do enoturismo auxilia a melhora da infraestrutura local, bem como a geração de empregos na área rural, fazendo com que moradores do entorno a até mesmo os jovens visualizem novas oportunidades de trabalho (DALLANHOL; TONINI, 2012, p. 131).
\end{abstract}

Cabe salientar que o enoturismo está centrado, especialmente, na aproximação do setor vitivinícola e dos turistas, motivados pela degustação, pela compra e pela compreensão do vinho (ATOUT FRANCE, 2010). Para Lignon-Darmaillac (2012), o termo 'Enoturismo' evoca uma atividade contraditória, pois a aliança entre o vinho e o turismo surpreende e provoca questionamentos, sem apresentar uma proposta concreta para a descoberta lúdica e cultural dos vinhedos, de suas empresas vitivinícolas, seus negócios e até mesmo sua história (LIGNON-DARMAILLAC, 2012).

As informações gerais sobre as qualidades dos vinhos são repassadas ao turista no momento da degustação, estimulando a identificação das características e diferenças de cada um, de modo a fazer com que essa atividade proporcione novos conhecimentos sobre os vinhos e contribua com a sua comercialização (DALLANHOL; TONINI, 2012, p. 32).

Para Protas e Camargo (2011), fica evidente a necessidade de se intensificar esforços no sentido de organizar as regiões vitivinícolas para a exploração do enoturismo, já que existe uma intensa competição da produção nacional de vinhos frente aos vinhos importados e outros produtos substitutos.

Ao longo deste estudo foi constatado, que em 10 (dez) dos empreendimentos vitivinícolas de altitude de Santa Catarina, já há a possibilidade de prática do enoturismo e que existem outros investidores vitivinícolas interessados em implantar algum produto ou serviço enoturístico. Neste sentido, enfatiza-se que nos últimos anos as características próprias de uma região para o cultivo da vinha e para a produção de vinhos finos estão sendo percebidas como um grande potencial para o desenvolvimento e incremento da atividade de enoturismo ou como complemento ao turismo existente na localidade (LOSSO; PEREIRA, 2012). 


\section{REFERENCIAL TEÓRICO-METODOLÓGICO}

Para realização desta pesquisa fez-se uso de uma matriz teórica apropriada ao entendimento do processo de implantação da vitivinicultura de altitude em Santa Catarina e tomou-se como ponto de partida a análise da realidade sócio-espacial, com base nos conceitos e nas ideias propostos por Milton Santos (1977). O paradigma de formação sócio-espacial se apoia na perspectiva teórica do materialismo histórico e dialético, inserindo a categoria espaço no conceito de formação econômica e social que abre novas e importantes aplicações aos estudos no campo da Geografia.

Aliado a este conceito chave, o trabalho teve apoio também nas ideias difundidas por André Cholley (1964) que sugere considerar, na análise da organização espacial, a combinação de elementos físicos, biológicos e humanos responsáveis por sua configuração ao longo do tempo. Portanto, na abordagem científica da temática proposta se considera a relação dialética entre os elementos naturais e humanos em múltiplas escalas, visando demonstrar que as explicações para o entendimento de qualquer realidade local precisam ser analisadas num universo mais amplo.

Este entendimento, por sua vez, coincide com a exigência marxista de estudos de caráter globalizante acerca da realidade alvo da investigação, que só poderá ser captada a partir da consideração das "múltiplas determinações" responsáveis por sua configuração. Assim sendo, na aplicação do paradigma de formação sócio-espacial fazse necessário considerar os aspectos físicos do espaço onde se instalaram as empresas dos setores de vitivinicultura de altitude e de enoturismo na área objeto do estudo, bem como a evolução da sociedade que ali se estabeleceu ou que deram origem a estas atividades da economia, numa interpretação que contemple as características naturais e humanas que, ao longo do tempo, definiram a sua trajetória.

Milton Santos discute o conceito de formação econômica e social, alertando para a ausência da categoria espaço, razão pela qual propõe o paradigma de formação econômica, social e espacial, partindo do entendimento de que "a história não se escreve fora do espaço e não há sociedade a-espacial” (SANTOS, 1982, p. 10). Assim, se o espaço é uma construção social, é necessário que o estudo de qualquer região leve em conta aspectos geográficos e históricos, partindo da esfera da produção. Por outro lado, uma análise espacial ampla, torna fundamental considerar as combinações resultantes da 
totalidade dos elementos que atuam sobre o espaço em questão. Assim, "quando procuramos reduzir a realidade geográfica a seus elementos mais simples, chegamos à noção de combinação de complexo, expresso, essencialmente, por fenômenos de convergência" (CHOLLEY, 1964, p. 139).

Ao aproximar o paradigma da formação sócio-espacial da noção de combinação de complexo de André Cholley (1964), no estudo se buscou identificar a convergência dos fenômenos ocorridos, tornando a combinação destes, parte da investigação. Na interpretação da realidade das regiões vitivinícolas de altitude de São Joaquim, Caçador e Campos Novos, nas quais a expansão da vitivinicultura pode ser reconhecida como um novo estímulo ao desenvolvimento regional e como incremento à estruturação da atividade enoturística, procurou-se determinar os caracteres das combinações existentes e as razões da convergência dos elementos que as compõem.

No desenvolvimento desta pesquisa se recorreu também ao aporte teórico aplicado por Armen Mamigonian (1986) em seus estudos sobre o sul do Brasil e, em particular, sobre Santa Catarina. Estes estudos foram fundamentados na categoria de pequena produção mercantil e se reportam ao dinamismo industrial das áreas de colonização europeia. No presente estudo, essa linha interpretativa foi aplicada no intuito de melhor compreender o processo de industrialização do vinho no âmbito regional, sua incidência e gênese relacionadas ao processo de colonização e a origem do capital dos novos investimentos vitivinícolas de altitude.

A instalação dos imigrantes, particularmente alemães e italianos, em pequenas propriedades no Sul do Brasil e especialmente em Santa Catarina, inicia um novo ciclo povoador caracterizado pela sucessão de correntes migratórias (PEREIRA, 2011). A autora infere que, em Santa Catarina, a pequena produção mercantil se insere paralela à estrutura latifundiária que caracterizou a ocupação de algumas áreas do Brasil Meridional, entre as quais as manchas de campo do planalto catarinense, demonstrando um dinamismo muito superior ao alcançado, por exemplo, pela pequena produção dos colonos açorianos, já que os imigrantes europeus do século XIX trouxeram consigo as bases do capitalismo industrial, propício ao surgimento e à consolidação da indústria catarinense.

Além disso, no que tange à abordagem metodológica, esse trabalho foi realizado através de pesquisa qualitativa, por sua utilidade como suporte para o pesquisador na 
apreensão da complexidade do tema investigado, permitindo assim, "compreender e classificar processos dinâmicos vividos por grupos sociais e possibilitar, em maior nível de profundidade, o entendimento das particularidades do comportamento dos indivíduos" (RICHARDSON, 1999, p. 43). A pesquisa qualitativa permite a obtenção de um conhecimento mais profundo de casos específicos (DENCKER, 2000), propiciando apreender a complexidade de determinada hipótese ou problema (OLIVEIRA, 1999).

Assim sendo, para atingir com êxito os propósitos deste estudo, realizou-se uma pesquisa histórica e exploratória, pois o caráter exploratório favorece uma maior familiaridade com o problema, com vistas a torná-lo mais explícito ou a construir hipóteses (GIL, 2002).

Por se caracterizar como um estudo preliminar centrou-se na revisão bibliográfica e documental buscando fatos históricos, informações e dados secundários que pudessem sustentar o desenvolvimento e a caracterização dos elementos físicos e humanos responsáveis pela configuração da geografia de vinhos finos de altitude do Estado de Santa Catarina, bem como sua inter-relação com as transformações da vitivinicultura no Brasil e no mundo, assim como a consolidação do enoturismo em regiões vitivinícolas. Portanto, a coleta de dados levou à consulta de livros, dissertações, teses e artigos de revistas científicas sobre o tema, assim como publicações técnicas, em revistas especializadas e na internet.

\section{NOTAS SOBRE A VITIVINICULTURA NO BRASIL E EM SANTA CATARINA}

O Brasil apresenta um crescimento importante no panorama mundial do vinho, resultado oriundo de um forte movimento de modernização dos vinhedos e do parque industrial vitícola, permitindo o aperfeiçoamento das tradicionais regiões, assim como a consolidação de novas áreas produtoras, fato que se reflete também nas premiações internacionais conquistadas por diferentes vinícolas brasileiras na última década, (IBRAVIN, 2014), incluindo vinícolas catarinenses (ACAVITIS, 2014). 
Porém, na presente pesquisa, considerou-se ser importante abordar sua discussão sobre a produção de vinhos finos de altitude em Santa Catarina a partir do desenvolvimento da atividade de vitivinicultura no Brasil, o que implica, inicialmente, mencionar a expansão do povoamento do território do país através dos fluxos de imigração europeia, visto que a origem e o desenvolvimento desta atividade estão intimamente relacionados à cultura destes povos, principalmente dos colonizadores portugueses e dos imigrantes italianos.

“A vitivinicultura brasileira inicia com a colonização portuguesa no século XVI, mas é com a imigração italiana, a partir da segunda metade do século XIX, que se configuram muitas das tradicionais regiões vitivinícolas atuais" (FALCADE, 2003, p. 134). Conforme Mello (2004) e Dalcin (2008), ainda no século XVI, foram plantadas as primeiras videiras nos Estados de São Paulo, Pernambuco e Bahia, porém, rapidamente percebeu-se que as condições climáticas do litoral não eram propícias ao cultivo da uva vinífera. Ainda assim, o cultivo de uvas viníferas progrediu a ponto de atender às necessidades particulares de então e ainda permitir um pequeno comércio local nestas regiões (MELLO, 2004; DALCIN, 2008).

No século XVII foram introduzidas as primeiras videiras no Rio Grande do Sul, na região dos Sete Povos das Missões, com o propósito do uso do vinho nas celebrações, assim como era comum nas demais regiões do país (DALCIN, 2008). Estas primeiras videiras desapareceram com a destruição das missões jesuítas, assim como não vingaram, em razão das condições climáticas, as plantas inseridas no litoral gaúcho (VALDUGA, 2007).

Na primeira metade do século XVIII, com a chegada dos imigrantes açorianos que povoaram a Região Sul do Brasil, a vitivinicultura ressurge no cenário do período colonial (MIELE; MIOLO, 2003; DALCIN, 2008). Entretanto, diante do lucrativo comércio das charqueadas, o cultivo da vinha praticado pelos açorianos no Rio Grande do Sul, por exemplo, teve pouca expressão na economia do período (MELLO, 2004).

As uvas americanas foram introduzidas no Brasil no século XIX, através do envio, de Washington (EUA), de mudas da variedade Isabel, realizado pelo gaúcho Marques Lisboa ao comerciante Thomas Messiter (DALLANHOL; TONINI, 2012). Esta fértil variedade foi inicialmente plantada na Ilha dos Marinheiros, próxima a cidade de Rio Grande (extremo sul do Estado do Rio Grande do Sul) e logo se expandiu, 
substituindo as uvas europeias que ainda resistiam às condições climáticas desfavoráveis ao seu cultivo (AGUIAR, 2008).

Contudo, a vitivinicultura no país ficaria restrita a pequenas áreas em distintos pontos do território nacional até o ano de 1875, quando tem início, na Serra Gaúcha (Rio Grande do Sul), a instalação de imigrantes italianos (FALCADE, 2003). Considera-se, então, como marco inicial da indústria vitivinícola brasileira, a chegada destes imigrantes italianos (século XIX) e sua instalação na Serra Gaúcha (CORDEIRO, 2006) que tiveram os imigrantes alemães como fornecedores de grande parte de suas videiras de Isabel, cultivadas no alto da região serrana (AGUIAR, 2008).

O imigrante italiano desenvolveu de imediato uma agricultura diversificada que em grande parte era voltada para o autoconsumo (CORDEIRO, 2006). Porém, para superar dificuldades de concorrência com a região de colonização alemã do estado do Rio Grande do Sul no comércio de produtos coloniais, a solução encontrada foi "a especialização na produção e comercialização do vinho" (SANTOS, 1980, p. 139).

A atividade de vitivinicultura teve grande importância para a fixação da cultura italiana no Sul do Brasil e principalmente, para o desenvolvimento econômico da região da Serra Gaúcha (AGUIAR, 2008). A autora ressalta que estes imigrantes italianos (provenientes em sua maioria do Norte da Itália) tinham experiência no cultivo da vinha e na produção do vinho e trouxeram consigo sua expressiva tradição, tornando-se um elemento facilitador para a transição de uma produção doméstica para o estabelecimento do comércio do vinho no país.

O processo de institucionalização da vitivinicultura brasileira se inicia em 1937 com a publicação da Lei federal $n^{\circ} 549$, conhecida como Lei federal do Vinho e que dispunha sobre a fiscalização da produção, circulação e distribuição de vinhos e derivados, incluindo a criação de respectivos serviços (BRASIL, 2014a). Segundo Aguiar (2008), a publicação da Lei do Vinho resultou em inúmeros postos de análise de vinho em centros de consumo e portos e no Laboratório Central de Enologia no Rio Grande do Sul. A autora destaca ainda, a criação das primeiras Estações Experimentais de Viticultura e Enologia em 1938 e que a da cidade de Bento Gonçalves seria absorvida pela Empresa Brasileira de Pesquisa Agropecuária Uva e Vinho - Embrapa Uva e Vinho no ano de 1975. 
De acordo com o Decreto $\mathrm{n}^{\circ}$ 8.198, de 20 de fevereiro de 2014 (BRASIL, 2014b), que regulamenta a Lei $\mathrm{n}^{\circ} 7.678$, de 8 de novembro de 1988 e dispõe sobre a produção, circulação e comercialização do vinho e derivados da uva e do vinho, são zonas de produção vitivinícola no Brasil as relacionadas nos seguintes estados (figura 2):

a) Rio Grande do Sul - nas regiões conhecidas como Alto Uruguai, Campanha, Campos de Cima da Serra, Depressão Central, Encosta do Sudeste, Encosta Inferior do Nordeste, Missões, Planalto Médio, Serra Gaúcha e Serra do Sudeste;

b) Santa Catarina - nas regiões conhecidas como Litoral Sul Catarinense, Planalto Catarinense, Vale do Rio do Peixe e Vale do Rio Tijucas;

c) Paraná - na Região da Grande Curitiba e Região de Maringá;

d) São Paulo - na Região de Jundiaí e na Região de São Roque;

e) Minas Gerais - nas regiões conhecidas como Cerrado Mineiro, Região Sul (Sudoeste de Minas) e no Vale do Alto São Francisco;

f) Espírito Santo - na Região Serrana do Espírito Santo;

g) Mato Grosso - na Região de Nova Mutum;

h) Goiás - na região do Centro-Sul Goiano;

i) Bahia - na Região de Petrolina e Juazeiro; e

j) Pernambuco - na Região de Petrolina e Juazeiro. 


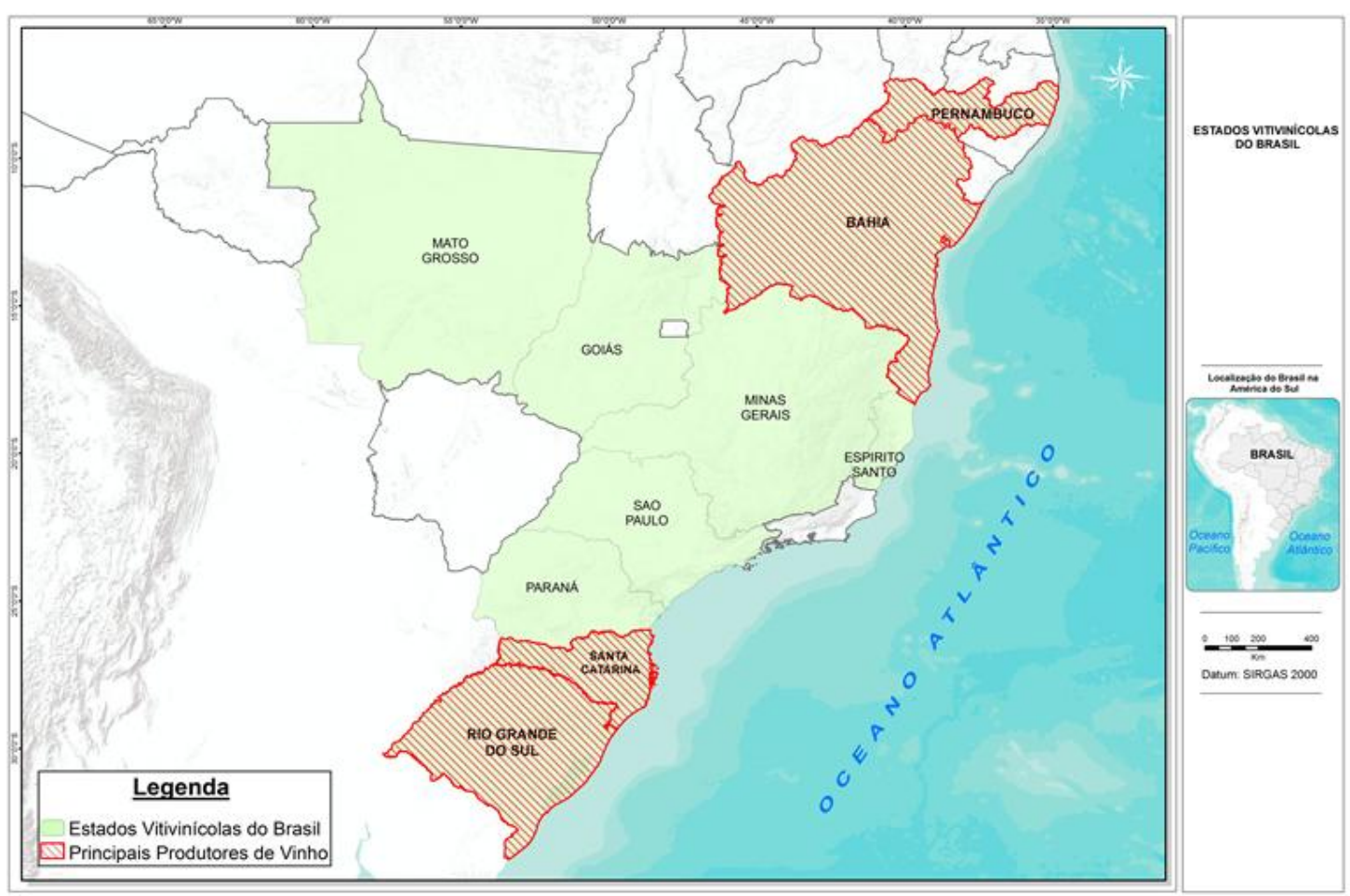

FIGURA 2 - ESTADOS VITIVINÍCOLAS DO BRASIL.

Elaboração: Flavia Baratieri Losso e Renata Duzzioni, 2014.

Fonte: BRASIL, (2014b).

Mais particularmente relacionado à Santa Catarina como foco deste artigo, a evolução da vitivinicultura apresenta características semelhantes ao ocorrido no estado do Rio Grande do Sul. Com a vinda dos colonizadores açorianos no século XVIII, surgem as primeiras tentativas de produzir vinhos no Estado e neste período, por motivos variados, a atividade não progrediu na Província de Santa Catarina (CORDEIRO, 2006). Foram as primeiras mudas de uva plantadas pelos imigrantes italianos que chegaram, em 1878, na região da cidade de Urussanga, as responsáveis pelo início da vitivinicultura catarinense (LOMBARDO, 2009). Porém, o autor aponta que se fez necessário recorrer às variedades americanas e híbridas, mais resistentes a pragas e ao clima tropical.

Os italianos também chegaram ao Vale do Rio Tijucas e se instalaram em 1875 em Nova Trento, onde mantiveram a tradição da cultura da uva e do vinho que são elaborados igualmente com as uvas americanas, sendo posteriormente associada ao turismo religioso através das peregrinações ao Santuário de Santa Paulina (CORDEIRO, 2006). 
No Meio-oeste, às margens do Rio do Peixe, famílias italianas, oriundas da Lombardia, se instalaram em 1884, como é o caso da família de Giuseppe Panceri que mantém suas atividades no setor vitivinícola desde então (LOMBARDO, 2009).

Em 1956, a família Frey começou o plantio, entre outras frutas de clima temperado, como foi o caso da maçã, de parreiras, construindo uma cantina e iniciando a produção de vinho (CORDEIRO, 2006). Anos mais tarde, em 1961, na tentativa de aprimorar seu produto oriundo da videira, a empresa da família Frey se associou a um grupo de fruticultores franceses que elaboravam vinhos na Argélia (DESPLOBINS, 2003). Segundo o autor, essa parceria foi responsável pelo plantio das primeiras videiras de castas europeias na região, que por falta de conhecimentos técnicos apropriados, resultou em uma experiência fracassada na época.

A produção da uva e do vinho no Meio-oeste catarinense é constituída principalmente de uvas de origem americana e híbrida, assim como a do mercado brasileiro (IBRAVIN, 2014; EPAGRI, 2004). Apesar de na década de 1990 ter ocorrido um decréscimo da área plantada com as uvas americanas e híbridas, devido ao alto custo de implantação dos vinhedos, um mercado próximo da saturação e problemas de morte e declínio de plantas (EPAGRI, 2004), a vitivinicultura do Alto Vale do Rio do Peixe é responsável por cerca de $80 \%$ da produção de uva e vinho no Estado catarinense (BRDE, 2005), mantendo sua tradição atrelada às origens de seus habitantes, como ocorre na Serra Gaúcha.

O caso da família Panceri é bastante exemplar, pois através das iniciativas dos irmãos Celso e Luiz, houve um redirecionamento das atividades de vitivinicultura, iniciadas, em 1958, por seu pai Nilo na região de Tangará (Meio Oeste catarinense), neto do italiano Giuseppe Panceri, que chegou à região de Caxias do Sul em 1884 (LOMBARDO, 2009). Os vinhedos de vitis viníferas começaram a ser implantados em 1999 posteriormente a Vinícola Panceri passou a ser exemplo por se tratar de uma empresa familiar, de origem italiana, instalada no município de Tangará desde o início da ocupação da região e por seu pioneirismo servir de referência para os novos empreendimentos surgidos na região, como a Vinícola Pisani (CORDEIRO, 2006).

No ano de 2012, foram produzidos 21,18 milhões de litros de vinhos em Santa Catarina, a qual a maior parte ainda é de vinhos de mesa, no caso, 72,57\% (MELLO, 2013). A autora constatou que ocorreu um aumento de $11,77 \%$ na produção de vinhos 
de mesa e uma redução de $19,15 \%$ na produção de vinhos finos em 2012, pois a safra de uvas viníferas utilizadas para a elaboração de vinhos finos foi prejudicada devido à ocorrência de chuva de granizo.

A marca, a enologia e a tecnologia se apresentam como as três forças que sustentam a vantagem competitiva na composição novo-mundista do vinho (AGUIAR, 2008). A autora evidencia que a nova configuração no campo do vinho transformou a produção consideravelmente, a partir do uso significativo de tecnologia, do conhecimento científico e da administração comercial estratégica, o que tornou o setor mais preparado e automatizado para corresponder aos anseios consumistas e expansionistas da atualidade.

Particularmente, a abertura comercial do Brasil, a partir da década de 1990, estimulou o consumo de vinhos importados através do aumento de opções de produtos diferenciados em termos de marcas, variedades e denominações de origem (TONIETTO, 2003a). Esta situação obriga o produto nacional, em fase de desenvolvimento de marcas e características organolépticas ainda recentes, a disputar o mercado interno de vinhos finos com marcas e produtos já consolidados e reconhecidos pelo consumidor brasileiro (BLUME; HOFF; PEDROZO, 2007).

Assim como a tecnologia vem sendo inserida na produção do vinho, também tem contribuído cada vez mais na comercialização da bebida, devido ao uso de recursos de gestão e marketing, ao uso da internet e demais facilidades de comunicação, assim como a valorização dos fluxos turísticos regionais por meio do incremento do enoturismo (DALLANHOL; TONINI, 2012).

Associado ao enoturismo, o interesse dos profissionais do vinho está no desenvolvimento das vendas e na fidelização do cliente, cabendo ao setor compor produtos que possam ser incorporados à oferta turística local ou regional (LIGNONDARMAILLAC, 2011). Porém, a autora destaca ainda, a importância do enoturismo para a diversificação e o fortalecimento da oferta turística, fato que, por definição, permite afirmar que o planejamento desta atividade deverá ser realizado pelos atores de ambos os setores, vitivinícola e turístico.

Realizar passeios pelos parreirais, poder degustar vinhos e adquiri-los na fonte são atividades ligadas a uma tipologia turística chamada enoturismo. Isso tudo porque o vinho não é um simples produto, mas o resultado de 
milhares de anos que formaram um terroir ${ }^{3}$, aliado à cultura de determinada sociedade, que faz com que um número considerável de pessoas viaje para conhecer (DALLANHOL; TONINI, 2012, p. 28).

Esta atividade porta-se como um grande negócio para a indústria do vinho, por garantir as vinícolas um rendimento paralelo, reforçando a venda direta dos produtos e possibilitando uma maior exposição da marca (ATOUT FRANCE, 2010). Por exemplo, na Serra Gaúcha e na região de Mendonza, na Argentina, esta atividade desponta como umas das principais ações do turismo regional (AGUIAR, 2008). Neste sentido, o enoturismo pode ser visto como uma alternativa para o consumidor que queira aprender sobre o vinho de modo mais informal, através de viagens organizadas para regiões vinícolas ou pela participação em festivais e feiras organizados por associações de produtores (LIGNON-DARMAILLAC, 2011).

As condições naturais e as realizações humanas nas regiões vitivinícolas no mundo formam, pois, "uma rede de relações, de cujo ordenamento os frutos constituem um todo complexo e uma realidade definida" (SANTOS, 2008, p. 116), e que, neste estudo, vem demonstrando um resultado pautado na constituição de uma oferta enoturística. Isto se deve ao fato de que o capitalismo se apresenta como um processo evolutivo, uma forma ou um método de mudança que nunca pode ser estacionário. No caso desta pesquisa, a análise esteve pautada em verificar a introdução e a difusão de inovações, que se tornam responsáveis pelas modificações das necessidades do homem, imprimindo transformações na estrutura da oferta de diversos setores da economia, especialmente, na produção da vitivinicultura e do enoturismo.

\section{A VITIVINICULTURA DE ALTITUDE CATARINENSE: UM ESPAÇO DE ENOTURISMO?}

Como consequência dessa reconfiguração da vitivinicultura no mundo vem ocorrendo, desde o final da década de 1990, uma reversão das expectativas no plantio

\footnotetext{
${ }^{3}$ Originário da França, terroir é um amplo conceito e reúne um conjunto de fatores que influenciam a qualidade do vinho. Solo e subsolo, clima geral e local (macro, meso e micro clima), exposição ao sol, altitude e inclinação do terreno, variedade e idade das cepas, sistemas de condução das parreiras, enfim, a intervenção do homem no plantio dos vinhedos e na elaboração do vinho, além de aspectos socioeconômicos e culturais somam características que vão expressar o caráter do vinho, sua personalidade e qualidade (LAROUSSE DO VINHO, 2007, p. 84).
} 
das variedades de castas europeias, que resultou no surgimento de novos plantios, inclusive em áreas não tradicionais para o cultivo da videira, como a região de elevada altitude (acima de 900 metros), no Planalto Catarinense, nos Campos de Água Doce, Caçador e Campos Novos, além das já tradicionais regiões como Tangará e Videira (KREUZ et. al., 2005).

Diante disso, passou a acontecer uma transformação na vitivinicultura do MeioOeste catarinense, através do plantio em escala comercial de vinhedos de castas viníferas desde o início da década de 2000 (CORDEIRO, 2006). O autor destaca que, até o ano de 2005, trinta e três produtores tinham plantado aproximadamente 106 hectares de vinhas esperando-se que essa região torne-se um importante ícone na produção de vinhos finos em Santa Catarina. Portanto, novas regiões produtoras surgiram:

[...] baseadas no conceito de altitude, paisagens e amor ao vinho, levam diferentes empresários de segmentos de sucesso (cerâmica, têxtil, fruticultura, madeira, metal mecânica, embalagens plásticas, entre outros) a entrar neste mercado, focados em altíssima qualidade. Grandes inversões, seja em vinícolas lindíssimas, ambiciosos projetos de marketing e posicionamento passam a acontecer, elevando a categoria do terroir catarinense como um dos mais promissores do país. Propõem vinhos considerados topo da pirâmide em preço e posicionamento, sem medir investimentos em qualidade (FLORES; FLORES, 2012, p. 67).

$\mathrm{Na}$ região de São Joaquim, identifica-se a nova geração de vinhos e de empresários que simbolizam a revolução experimentada pela vitivinicultura catarinense, em busca de modernização para alcançar um novo patamar de mercado na virada para o século XXI (LOMBARDO, 2013). Entretanto, é importante reconhecer que as bases lançadas pelos imigrantes italianos sedimentaram e consolidaram a atividade vitivinícola em Santa Catarina (KREUZ et. al., 2005), especialmente no Vale do Rio do Peixe e no Litoral Sul catarinense.

As condições geográficas da região do planalto catarinense tiveram um papel fundamental na introdução e desenvolvimento da produção de uvas, especialmente as da variedade vitis viníferas (BRDE, 2005), visto que:

[...] a região do planalto catarinense apresenta características climáticas com a predominância de invernos rigorosos, primavera e verão amenos, além de outono com alternância de temperaturas diurnas e noturnas e baixo índice pluviométrico na época de maturação e de colheita da uva (BONIN; BRIGHENTI, 2005). 
Entretanto, é importante ressaltar que a região de São Joaquim apresenta diversas condições mesoclimáticas, condições estas que podem ser interessantes para a maturação de variedades de uvas mais tardias, beneficiando a qualidade do vinho (BRIGHENTI; TONIETTO, 2004). A influência climática dada à altitude proporciona o deslocamento do ciclo produtivo da videira que, beneficiado pelas condições geoclimáticas da altitude catarinense, propicia a elaboração de vinhos mais alcoólicos, com uma coloração intensa e apresenta uma aceitação importante pelos consumidores de vinhos finos de altitude e pela área especializada (sommeliers, enólogos e enófilos) (ROSIER, 2003) apesar de se identificar especialistas que julguem o teor alcoólico elevado como uma desvantagem da altitude, como por exemplo, Lalas (2013).

Assim, pois, a altitude cria condições específicas de clima capazes de contribuir no cultivo da vinha. A cada 100 metros acima do nível do mar, o ar perde $1 \%$ de seu carbono, o que representa dizer que nas manchas de altitude do Planalto Catarinense há em média $10 \%$ a menos desse elemento na sua atmosfera, resultando num processo vegetativo mais lento (ACAVITIS, 2010). A pressão atmosférica menor e a maior proximidade do sol têm ação sobre a evaporação nas folhas, que eliminam mais água do que o normal, concentrando os nutrientes que vêm do solo e formando a seiva rica de alimentação das bagas de uva (BRIGHENTI; TONIETTO, 2004). Por fim, a temperatura baixa durante a noite faz com que a respiração das folhas seja menor, economizando carbono (ACAVITIS, 2010).

Quanto às especificidades da recente produção de vinhos finos de altitude e suas características, os empresários do setor vitivinícola da região de São Joaquim, demonstraram serem unânimes em relação ao desempenho da variedade Cabernet sauvignon e concentraram sua produção em vinhos oriundos desta casta (LOSSO, 2010). Porém, a mesma autora constatou que há uma busca pela especificidade regional, através do cultivo de castas menos comuns ao Brasil vitivinícola e ainda utilizadas em pequena escala na fabricação de vinhos finos brasileiros, como é o caso das castas portuguesas e italianas, em oposição às castas francesas.

A qualidade dos vinhos finos de altitude de Santa Catarina passou a ser reconhecida pouco tempo depois do lançamento de seus primeiros vinhos. Na 
Expovinis ${ }^{4}$ 2007, entre os 25 melhores vinhos nacionais selecionados pela Associação Brasileira de Sommeliers (ABS), 4 vinhos eram provenientes de associados da ACAVITIS e classificaram-se entre os dez melhores, obtendo, inclusive, o primeiro lugar (LOSSO, 2010). Neste mesmo concurso, o Villa Francioni Chardonnay 2006 foi o único vinho branco brasileiro que se destacou entre grandes expoentes mundiais (BRDE, 2007). Além disso, outras dentre as vinícolas de altitude já tiveram seus vinhos premiados, como é o caso da Suzin, Pericó, Villaggio Grando, Santa Augusta, Kranz, Sanjo, Quinta da Neve e Abreu Garcia (ACAVITIS, 2014).

A vitivinicultura de altitude passa a ser desenvolvida no planalto catarinense a partir de estudos iniciados na década de 1990 pela Empresa de Pesquisa Agropecuária e Extensão Rural de Santa Catarina - EPAGRI, e atraiu investimentos de empresas de outras regiões já ao final desta década (CORDEIRO, 2006). A produção de vinhos finos de altitude continuou em expansão, tendo empresários motivados pelas características geoclimáticas e também pela possibilidade de empregar sofisticadas técnicas enológicas, utilizando modernas instalações produtivas, como ocorreu nos primeiros investimentos (BRDE, 2007).

Cabe destacar que a produção de vinhos finos de altitude em Santa Catarina concentra-se em três regiões produtoras (Campos Novos, Caçador e São Joaquim) que integram a Associação Catarinense de Produtores de Vinhos Finos de Altitude ACAVITIS, criada em 2005 com o intuito de promover uma marca de qualidade. As normas da ACAVITIS fixam alguns parâmetros para a produção que garantem o padrão e a qualidade dos vinhos finos de altitude de Santa Catarina, como a altitude acima de 900 metros em relação ao nível do mar, a produção máxima de seis mil litros de vinho por hectare de uva plantada, além da proibição da chaptalização ${ }^{5}$ (LOSSO, 2010).

O referencial teórico utilizado neste estudo (SANTOS, 1977; CHOLLEY, 1964; MAMIGONIAN, 1986) evidencia o dinamismo da vitivinicultura na região de São Joaquim, apontando para os investimentos pioneiros da Vinícola Quinta da Neve, com vinhedo implantado no ano 2000 e o primeiro vinho lançado em 2004, e da Vinícola Villa Francioni, com vinhedos implantados em 2001 e o lançamento do primeiro vinho

\footnotetext{
${ }^{4}$ A Expovinis é o maior evento do setor de vinhos na América Latina, realizada anualmente em São Paulo, onde são apresentados vinhos nacionais e importados.

${ }^{5}$ Adição de açúcar ao mosto no intuito de elevar o teor alcoólico dos vinhos tranquilos.
} 
em 2005 (LOSSO, 2010). Entre os empresários, há pessoas descendentes de italianos do Sul do Estado de Santa Catarina, do Estado do Rio Grande do Sul e do Estado do Paraná, regiões cujo capital tem origem na pequena produção mercantil do Sul do Brasil, onde se instalaram os imigrantes, definindo e dinamizando estas áreas coloniais (LOSSO; PEREIRA, 2012).

Entre os investidores pioneiros dessa nova fase da vitivinicultura catarinense, além das empresas já citadas, se destacam os seguintes investimentos que no ano de 2011 já comercializavam seus vinhos ${ }^{6}$ : Vinícola Suzin, São Joaquim, 2001; Quinta Santa Maria, São Joaquim, 2004; Sanjo, São Joaquim, 2002; Santo Emílio, Urupema, 2004; Serra do Sol, Urubici, 2004; Pericó, São Joaquim, 2007; e Villaggio Bassetti, São Joaquim, 2005 (LOSSO; PEREIRA, 2012). No ano de 2012 duas novas vinícolas Vinhedos do Monte Agudo e Vinícola Hiragami - lançaram seus vinhos no mercado nacional, o que demonstra a potência e a força empreendedora ligada à atividade nessa porção do território catarinense.

Dentre as 28 vinícolas associadas à ACAVITIS, 15 destas compõem o catálogo on line de produtos da COOPERVITIS ${ }^{7}$, onde além de apresentar seus produtos ao mercado consumidor, informam sobre a filosofia de trabalho e as origens de algumas empresas (ACAVITIS, 2014). No quadro 1 se apresentam as vinícolas associadas que já estão comercializando seus vinhos, distribuídas por região produtora, município de localização dos vinhedos, ano de lançamento dos primeiros vinhos e se há instalações para a recepção de turistas. Percebe-se que há uma concentração dos investimentos na região de São Joaquim e que a grande maioria das empresas com vinhos lançados vem, igualmente, se estruturando para receber turistas.

\footnotetext{
${ }^{6}$ Informações apresentadas - nome da empresa vitivinícola, localização do vinhedo, ano de fundação.

${ }^{7}$ A ACAVITIS conta com a Cooperativa dos Produtores de Vinhos Finos de Altitude - COOPERVITIS, braço comercial responsável pela promoção, a partir do estado de São Paulo e para todo o Brasil, das vendas coletivas dos vinhos de altitude de Santa Catarina. Esta estrutura institucional irá promover as vendas conjuntas - sem intermediários e com preços competitivos - dos aproximadamente 180 rótulos de vinhos de alta qualidade produzidos por vinícolas filiadas à associação (COOPERVITIS, 2014).
} 
QUADRO 1 - VINÍCOLAS ASSOCIADAS À ACAVITIS.

\begin{tabular}{|c|c|c|c|c|}
\hline EMPRESA & $\begin{array}{c}\text { REGIÃO } \\
\text { PRODUTORA }\end{array}$ & LOCALIZAÇÃ̃O & $\begin{array}{c}\text { ANO DE } \\
\text { LANÇAMENTO } \\
\text { DOS VINHOS }\end{array}$ & $\begin{array}{c}\text { APRESENTA } \\
\text { ESTRUTURA DE } \\
\text { ENOTURISMO }\end{array}$ \\
\hline Abreu Garcia & São Joaquim & $\begin{array}{l}\text { Campo Belo do } \\
\text { Sul }\end{array}$ & 2011 & $\begin{array}{c}\text { Sim } \\
\text { (em fase de reformas) }\end{array}$ \\
\hline Casa Pisani & Campos Novos & Monte Carlo & 2010 & Site não identificado \\
\hline $\begin{array}{l}\text { Quinta da } \\
\text { Neve }\end{array}$ & São Joaquim & São Joaquim & 2004 & Não \\
\hline $\begin{array}{l}\text { Quinta Santa } \\
\text { Maria }\end{array}$ & São Joaquim & São Joaquim & 2009 & Sim \\
\hline Sanjo & São Joaquim & São Joaquim & 2009 & Sim \\
\hline Serra do Sol & São Joaquim & Urubici & 2009 & Não \\
\hline $\begin{array}{l}\text { Villa } \\
\text { Francioni }\end{array}$ & São Joaquim & São Joaquim & 2005 & Sim \\
\hline $\begin{array}{l}\text { Villaggio } \\
\text { Bassetti }\end{array}$ & São Joaquim & São Joaquim & 2011 & Não \\
\hline $\begin{array}{l}\text { Villaggio } \\
\text { Grando }\end{array}$ & Caçador & Água Doce & 2006 & Sim \\
\hline $\begin{array}{l}\text { Vinhedos do } \\
\text { Monte Agudo }\end{array}$ & São Joaquim & São Joaquim & 2012 & Sim \\
\hline $\begin{array}{l}\text { Vinícola } \\
\text { Hiragami }\end{array}$ & São Joaquim & São Joaquim & 2012 & Não \\
\hline $\begin{array}{l}\text { Vinícola } \\
\text { Kranz }\end{array}$ & Caçador & $\begin{array}{l}\text { (uvas de parceiros } \\
\text { das } 3 \text { regiões) }\end{array}$ & 2011 & Sim \\
\hline $\begin{array}{l}\text { Vinícola } \\
\text { Panceri }\end{array}$ & Caçador & Tangará & 2001 & Sim \\
\hline $\begin{array}{l}\text { Vinícola } \\
\text { Pericó }\end{array}$ & São Joaquim & São Joaquim & 2008 & Não \\
\hline $\begin{array}{l}\text { Vinícola } \\
\text { Santa } \\
\text { Augusta }\end{array}$ & Caçador & $\begin{array}{l}\text { Videira / Água } \\
\text { Doce }\end{array}$ & 2008 & Sim \\
\hline $\begin{array}{l}\text { Vinícola } \\
\text { Santo Emílio }\end{array}$ & São Joaquim & Urupema & 2007 & Sim \\
\hline $\begin{array}{l}\text { Vinícola } \\
\text { Suzin }\end{array}$ & São Joaquim & São Joaquim & 2008 & Não \\
\hline
\end{tabular}

Fonte: ACAVITIS (2014); LOSSO (2010); e sites das vinícolas (2014).

Na região do Alto Vale do Rio do Peixe, onde estão localizados os polos produtores de Caçador e Campos Novos, a produção de uvas finas ainda é pequena em relação às uvas americanas, cerca de 5\% do total (PROTAS; CAMARGO, 2011). O quadro apresenta as empresas que estão cultivando uvas viníferas e produzindo vinhos finos em regiões de altitude do Meio-Oeste catarinense, como por exemplo, a Casa Pisani, a Villaggio Grando, a Kranz, a Panceri e a Santa Augusta, além das empresas localizadas na região produtora de São Joaquim.

No Meio-Oeste catarinense, cabe destaque o projeto da Vinícola Panceri, localizado no município de Tangará, possui uma ligação com a tradicional produção de vinhos de mesa, porém, nos últimos anos, vem modernizando sua produção e 
diversificando o seu foco de mercado, apresentando, desde 2001, além dos tradicionais vinhos de mesa, vinhos finos de altitude, espumantes, espumante Niágara (uva americana) e suco de uva (PROTAS; CAMARGO, 2011). Além disso, a vinícola possui estrutura para o atendimento de turistas, com varejo e museu da viticultura regional (PANCERI, 2014).

Além do importante papel dos órgãos de pesquisa, as linhas de crédito auxiliaram alguns empresários a implantarem seus vinhedos ou a adquirir equipamentos para o cultivo da uva europeia, conforme entrevistas realizadas em Losso (2010), com Acari Amorim (Quinta da Neve), Nazário Santos (Quinta Santa Maria), Everson Suzin (Vinícola Suzin), dentre outros.

\begin{abstract}
O BRDE opera com as linhas de crédito instituídas pelo BNDES, entre elas o Programa Nacional de Fortalecimento da Agricultura Familiar - PRONAF e o Programa de Desenvolvimento da Fruticultura - PRODEFRUTA, com vistas a que tais investimentos proporcionem o incremento da produtividade $\mathrm{e}$ da produção, assim como as melhorias do padrão de qualidade e das condições de comercialização dos produtos frutícolas (BRDE, 2005, p. 53).
\end{abstract}

Cabe ressaltar que estas linhas de financiamento não foram estabelecidas especificamente à vitivinicultura e muitas vezes o prazo de carência precede significativamente ao tempo de retorno de tais investimentos, já que além de cultivar a uva, o vinho é produzido e, normalmente, as primeiras safras que serão aproveitadas para a comercialização e lançamento de um primeiro vinho ocorrem depois de 3 ou 4 anos de vinhedo instalado (LOSSO, 2010).

Conforme estudo realizado por Mondo e Costa (2010), os principais mercados internos de sete vinícolas ${ }^{8}$ de altitude de Santa Catarina são os estados do Sul do Brasil (Rio Grande do Sul, Santa Catarina e Paraná), os estados do Sudeste (São Paulo, Rio de Janeiro, Espírito Santo e Minas Gerais) e o Distrito Federal. Os autores destacam ainda, que dentre tais vinícolas, duas possuem clientes nos Estados Unidos e na República Tcheca.

Ao se estudar a vitivinicultura de altitude catarinense, observa-se a existência de significativos acertos no processo de desenvolvimento do setor. A identificação de

\footnotetext{
${ }^{8}$ As vinícolas que participaram da pesquisa são consideradas vinícolas de destaque no estado de Santa Catarina, pois compõem a associação do setor do estado. Estão localizadas em sua maior parte no planalto serrano e meio oeste. A cidade de São Joaquim possui três das sete vinícolas do estudo, sendo as outras quatro distribuídas nas cidades de Água Doce, Videira, Tangará e Urubici (MONDO; COSTA, 2010, p. 174).
} 
recursos naturais raros e diferenciados se apresenta como um fator capaz de gerar vantagens competitivas, estruturando a atividade produtiva com o foco na segmentação de mercado.

O suporte de instituições de pesquisa como mecanismo de desenvolvimento de todo o setor produtivo, a articulação entre os recursos disponíveis, os maiores investimentos em publicidade e propaganda e os projetos que visam o diferencial do produto afirmado pelas indicações geográficas tendem a chamar a atenção para as tipicidades que procedem dos vinhos finos de altitude, confirmando a criação de um produto diferenciado no país (LOSSO, 2010). "Percebe-se que, apesar de ainda estarem em seu desenvolvimento inicial, as vinícolas já possuem estrutura suficiente para competir em diversos mercados, inclusive o internacional" (MONDO; COSTA, 2010, p. 174).

De certo modo, os responsáveis pelas vinícolas apresentadas até o presente expressaram seu interesse na busca pela qualidade e na estratégia do produto diferenciado, como estratégia para salvaguardar a competitividade, mobilizando o desejo de consumo pela singularidade, isto é, a atração e valorização do produto pelas características únicas obtidas nas áreas de altitude da serra catarinense (LOSSO; PEREIRA, 2012; MONDO; COSTA, 2010).

Neste sentido, os dirigentes das recentes empresas vitivinícolas instaladas nas regiões de altitude de Santa Catarina demonstraram o interesse em desenvolver suas instalações para a promoção do enoturismo, conforme demonstrado ao longo do artigo, e especialmente neste ano de 2014 realizaram a $1^{\text {a }}$ Vindima de Altitude de Santa Catarina $^{9}$, entre os dias 11 e 13 de abril, proporcionando o desenvolvimento da atividade por meio da articulação dos diversos atores públicos e privados.

\section{CONSIDERAÇÕES FINAIS}

As transformações ocorridas na vitivinicultura brasileira nas décadas de $1980 \mathrm{e}$ 1990 estabeleceram um novo referencial de qualidade para a produção de vinhos

\footnotetext{
${ }^{9}$ A $1{ }^{\text {a }}$ Vindima de Altitude de Santa Catarina foi promovida pela ACAVITIS e pelo SEBRAE, com o apoio do Governo do Estado. O evento reuniu 18 vinícolas dos municípios de São Joaquim, Urupema, Videira, Treze Tílias e Água Doce, apresentando palestras sobre o enoturismo nas regiões produtoras, degustações, visitações, almoços, piqueniques e sunset nas empresas.
} 
nacionais, marcado pelo crescimento na produção e no consumo de vinhos finos nacionais de filosofia similar àquela de outros países produtores do Novo Mundo, centrada nos vinhos varietais.

Neste estudo foi possível identificar a expressão dos investimentos da região de São Joaquim dentre os três polos produtores de vinhos finos de altitude catarinense, que representam cerca de $50 \%$ da área plantada pelos associados da ACAVITIS. Esta associação é composta por 28 empresas ou projetos vitivinícolas, integralizando uma área aproximada de 300 hectares de vinhedos com variedades de uvas europeias, exclusivamente voltadas para a elaboração de vinhos finos e espumantes.

Conforme ressaltado ao longo do artigo, os empresários pioneiros do setor vitivinícola de altitude das regiões de São Joaquim, Campos Novos e Caçador estão ligados a diferentes setores além da vitivinicultura tradicional, como o setor têxtil, o cerâmico, a fruticultura, a indústria madeireira, a pecuária e a comunicação, por exemplo, e muitos são externos à região onde se instalaram. Sendo assim, a inserção de capital externo e em uma nova atividade econômica tende a promover $\mathrm{o}$ desenvolvimento regional, pelas possibilidades de investimentos gerados e pela inserção de uma nova dinâmica à formação sócio espacial.

Com a inserção da vitivinicultura nas regiões de altitude catarinense, surge a oferta do enoturismo, que desponta como uma atividade promissora, capaz de redirecionar a economia regional, apresentando-se como uma consequência aos investimentos vitivinícolas instalados. Até o ano de 2014, 10 empresas vitivinícolas localizadas em São Joaquim, Urupema, Campo Belo do Sul, Água Doce, Treze Tílias, Tangará e Videira oferecem serviços enoturísticos, como visitações aos vinhedos e às instalações de produção, degustações, refeições e hospedagem.

\section{REFERÊNCIAS}

ACAVITIS. Associação Catarinense de Produtores de Vinhos Finos de Altitude. A altitude. Disponível em: <http://www.acavitis.com.br/site/web/site_dev.php/content/index/p/altitudeapresentacao>. Acesso em: 18/07/2010. 
Associados.

Disponível

em:

<http://www.acavitis.com.br/site/web/site_dev.php/associados $>$.

Acesso

em: 05/03/2014.

AGUIAR, M. O vinho na era da técnica e da informação: um estudo sobre Brasil e Argentina. Belo Horizonte: Autêntica, 2008.

ATOUT FRANCE. Tourisme et vin: les clienteles françaises et internationals, les concurrents de la France. Comment rester competitive? n 10. p? 3-95. 2010.

BRDE. BANCO REGIONAL DE DESENVOLVIMENTO DO EXTREMO SUL (Florianópolis). Vitivinicultura em Santa Catarina: situação atual e perspectivas. Florianópolis: BRDE, 2005. 83 p.

Produção de vinhos finos de altitude no planalto catarinense: requisitos e pleito de extensão de prazo de carência da linha de financiamento BNDS Automático para projetos de vitivinicultura de altitude. Florianópolis: BRDE, 2007. 19 p.

BONIN, V; BRIGHENTI, E. Situação atual e tendências da vitivinicultura de São Joaquim. In: SEMINÁRIO NACIONAL SOBRE FRUTICULTURA DE CLIMA TEMPERADO, 2005, São Joaquim. Resumo de palestras. São Joaquim: Epagri, 2005. p. $68-71$.

BLUME, R.; HOFF, D. N.; PEDROZO, E. A. Potencialidade competitiva e recursos essenciais à produção de vinhos finos: um estudo da vitivinicultura em São Joaquim, SC. In: XLV CONGRESSO BRASILEIRO DE ECONOMIA E SOCIOLOGIA RURAL, 2007, Londrina. Anais... Londrina: SOBER, 2007.

BRASIL, Presidência da República. Lei n $^{\circ}$ 549. 20 out. 1937. Disponível em: $<$ http://legis.senado.gov.br/legislacao/ListaNormas.action?numero=549\&tipo_norma=L EI\&data $=19371020 \&$ link=s $>$. Acesso em: 10/02/2014a.

Decreto $\mathbf{n}^{\mathbf{8}} \quad \mathbf{8 . 1 9 8}$. 20 fev. 2014. Disponível em: $<$ http://presrepublica.jusbrasil.com.br/legislacao/113703666/decreto-8198-14>. Acesso em: 21/02/2014b.

CHOLLEY, A. Observações sobre alguns pontos de vista geográficos. Boletim geográfico. Rio de Janeiro: CNG, mar./abr. 1964.

COOPERVITIS - Cooperativa dos Produtores de Vinhos Finos de Altitude. Catálogo. Disponível em: <http://www.coopervitis.com.br/catalogo/>. Acesso em: 05/03/2014.

CORDEIRO, W. A vitivinicultura em São Joaquim - SC: uma nova atividade no município. Dissertação (Mestrado). Programa de Pós-graduação em Agroecossistemas. UFSC. Florianópolis: 2006. 132 p.

DALLANHOL, E. B.; TONINI, H. Enoturismo. São Paulo: ALEPH, 2012. 
DALCIN, M. S. Vale dos Vinhedos: história, vinho e vida. Bento Gonçalves: MSD Empreendimentos Culturais; Gráfica Pallotti, 2008.

DENCKER, A. F. M. Métodos e Técnicas em Turismo. São Paulo: Futura, 2000.

DESPLOBINS, G. Tradition paysanne et modernisme industriel dans la vitiviniculture Sud-Brésilienne. Montpellier: 2003, mimeo.

EPAGRI. Normas técnicas para o cultivo da videira em Santa Catarina. Florianópolis: Epagri, 2004 (Normas Técnicas).

FALCADE, I. Paisagens vitícolas brasileiras. In: CONGRESSO BRASILEIRO DE VITICULTURA E ENOLOGIA, 10. p. 133-136. Anais... Bento Gonçalves: Embrapa Uva e Vinho, 2003.

A paisagem como representação espacial: a paisagem como símbolo das indicações geográficas de procedência de vinhos das regiões Vale dos Vinhedos, Pinto Bandeira e Monte Belo (Brasil). Tese (Doutorado). Programa de Pós-graduação em Geografia. IGEO/UFRGS. Porto Alegre: 2011. 309 p.

FLORES, M. A. D.; FLORES, A. Diagnóstico do Enoturismo Brasileiro. Brasília: SEBRAE; Bento Gonçalves: IBRAVIN, 2012. 126 p.

GIL, A. C. Como elaborar projetos de pesquisa. São Paulo: Atlas, 2002.

IBRAVIN - INSTITUTO BRASILEIRO DO VINHO. Panorama Geral. Disponível em: <http://www.ibravin.org.br/panorama-geral>. Acesso em: 12/02/2014.

KREUZ, C. L. ; SOUZA, A. ; SCHUCK, Ê. ; PETRI, J. L. Avaliação econômica de alternativas de investimentos no agronegócio da uva no meio oeste Catarinense. Revista Brasileira de Fruticultura. v. 27, n. 2. Jaboticabal: 2005. Disponível em: <http://www.scielo.br/scielo.php?pid=S0100-29452005000200012\&script=sci_arttext $>$. Acesso em: 16/04/2010.

LALAS, A. Para o alto: É possível compensar a pouca latitude com maior altitude nos vinhedos? Revista Adega. Ed. 91, mai. 2013. Disponível em: <http://revistaadega.uol.com.br/artigo/para-o-alto_5463.html>. Acesso em: 25/02/2014.

LAROUSSE DO VINHO. 2 ed. São Paulo: Larousse do Brasil, 2007.

LIGNON-DARMAILLAC, S. Vin, Vignobles et Tourisme: des relations à construire. Cahiers Espaces. n. 111. p. 8-14, 2011.

LOMBARDO, J. A. Santa Catarina à mesa: a revolução das uvas e do vinho e o renascimento das cervejarias no estado. 2. ed. Florianópolis: Editora Expressão, 2009.

Planalto Catarinense. Revista Anuário Vinhos do Brasil. Rio de Janeiro, p. 106-112, 2013. Edição especial. 
LOSSO, F. B. A produção de vinhos finos de altitude na região vitivinícola de São Joaquim (SC): uma alternativa para o turismo? Dissertação (Mestrado). Programa de Pós-graduação em Turismo e Hotelaria. UNIVALI. Balneário Camboriú: 2010. 206 p.

PEREIRA, R. M. F. do A. O desenvolvimento da vitivinicultura e as possibilidades de implantação de roteiros enoturísticos na região de São Joaquim (SC, Brasil). Revista Brasileira de Pesquisa em Turismo, São Paulo, v. 6, n. 2, p. 181-200, 2012.

MAMIGONIAN, A. Indústria de Santa Catarina. In: Relatório do Projeto Integrado de Pesquisa: Santa Catarina Sociedade e Natureza. CNPq, 2000. Versão atualizada da originalmente publicada no Atlas de Santa Catarina. Florianópolis: GAPLAN, 1986.

MILAN, E. Vinho de mesa ou vinho fino? Eis a questão. Revista Adega. Ed. 58, ago. 2010. Disponível em: <http://revistaadega.uol.com.br/artigo/vinho-de-mesa-ou-vinhofino-eis-a-questao_2488.html>. Acesso em: 20/01/2014.

MONDO, T. S.; COSTA, J. I. P. da. Estratégias de Marketing das Vinícolas Catarinenses. Revista Gestão Organizacional - RGO. v. 3, n. 2, p. 163-181, 2010. Disponível em:

<http://bell.unochapeco.edu.br/revistas/index.php/rgo/article/viewFile/692/453>.

Acesso em: 10/07/2013.

MELLO, C. E. C. de. Presença do vinho no Brasil: um pouco de história. São Paulo: Editora de Cultura, 2004.

MELLO, L. M. R. de. Vitivinicultura Brasileira: Panorama 2012. Comunicado Técnico. n. 137, p. 1-5, 2012. Disponível em:

<http://www.uvibra.com.br/pdf/Panorama\%202012\%20\%20Vitivinicultura\%20Brasilei ra.pdf>. Acesso em: 25/02/2014.

MIELE, A; MIOLO, A. O sabor do vinho. Bento Gonçalves: Vinícola Miolo: Embrapa Uva e Vinho, 2003. 136 p.

OLIVEIRA, S. L. D. Tratado de metodologia científica. São Paulo: pioneira, 1999.

PANCERI - Vinícola Panceri. Enoturismo. Disponível em:

<http://www.panceri.com.br/enoturismo.php\#ampliar/4/>. Acesso em: 25/02/2014.

PEREIRA, R. M. do A. Santa Catarina no contexto da formação sócio-espacial do Brasil Meridional: do período colonial ao início do século XX. In: MAMIGONIAN, A. (Org.). Santa Catarina: Estudos de geografia econômica e social. Florianópolis: GCN/CFH/UFSC, 2011, p. 13-30.

PROTAS, J. F. da S.; CAMARGO, U. A. Vitivinicultura brasileira: panorama setorial de 2010. Brasília: SEBRAE; Bento Gonçalves: IBRAVIN / Embrapa Uva e Vinho, 2011. 110 p. 
RICHARSON, R. J. Pesquisa Social: métodos e técnicas. 3 ed. São Paulo: Ed. Atlas, 1999.

ROSIER, J. P. Novas regiões: vinhos de altitude no sul do Brasil. In: CONGRESSO BRASILEIRO DE VITICULTURA E ENOLOGIA, 10. 2003, Bento Gonçalves. Anais... 2003.

SANTOS, M. Sociedade e Espaço: a formação social como teoria e como método. Boletim Paulista de Geografia, n. 54, p. 81-100. São Paulo: AGB, 1977.

Espaço e Sociedade. 2. ed. Petrópolis: Vozes, 1982.

Metamorfoses do espaço habitado: fundamentos teóricos e metodológicos da geografia. 6. ed. São Paulo: Edusp, 2008.

SANTOS, J. V. T. dos. Cantineiros e colonos: a indústria do vinho no Rio Grande do Sul. In: BARROS, E. C. RS: Imigração \& Colonização. Porto Alegre: Mercado Aberto, 1980. p. 135-155.

TONIETTO, J. Indicações geográficas para vinhos brasileiros. Jul. 2003a. Disponível em:

<http://sistemasdeproducao.cnptia.embrapa.br/FontesHTML/Uva/UvasViniferasRegioe sClimaTemperado/indicacoes.htm>. Acesso em: 20/04/2010.

Vinhos Brasileiros de $4^{\text {a }}$ Geração: O Brasil na era das Indicações Geográficas. Bento Gonçalves: Jun. 2003b. Disponível em:

<http://ainfo.cnptia.embrapa.br/digital/bitstream/item/26009/1/ComT45.pdf>. Acesso em: 10/12/2012.

VALDUGA, V. O processo de desenvolvimento do enoturismo no Vale dos Vinhedos. Dissertação (Mestrado). Programa de Pós-graduação em Turismo. UCS. Caxias do Sul: 2007. 149 p.

Recebido em: 15-05-2014.

Aprovado em: 13-06-2014. 